\title{
GPR imaging of dual-porosity rocks: Insights to fluid flow
}

Georgios P. TSOFLIAs, The University of Kansas, Lawrence, USA

$\mathrm{D}$ ual-porosity rocks, such as those that are fractured and/ or karstic, are highly heterogeneous and present a great challenge to predicting fluid-flow properties.

This study describes the potential of ground-penetrating radar (GPR) for meeting that challenge.

Field data were acquired at two fractured-rock hydrologic test sites which had been studied extensively prior to the GPR work presented here, and these earlier investigations allowed controlled testing of the GPR methods.

GPR imaging of carbonate lithofacies, flow units, and flow conduits

GPR reflection surveying was used to image the fractured Silurian Byron dolomite at Bissen Quarry. The site, in Door County, Wisconsin, is part of a regional aquifer along the western flank of the Michigan Basin. Lithology and horizontal stratigraphic discontinuities control the distribution of preferred flow paths and fluid storage capacity. Flow conduits form along bedding planes, diagenetic surfaces, and cycle sequence boundaries, and are further enhanced by dissolution. The Byron dolomite contains approximately $10 \mathrm{~m}$ of closely spaced depositional cycles associated with open and restricted marine facies.

Prior hydrologic studies identified four major horizontal bedding plane fractures ( $\mathrm{f} 1$ at $1.35 \mathrm{~m}, \mathrm{f} 2$ at $4.25 \mathrm{~m}, \mathrm{f} 3$ at 6.4 $\mathrm{m}$, and $\mathrm{f} 4$ at $12 \mathrm{~m}$ below surface), two dissolution zones (z1 at $2.72 \mathrm{~m}$ and z3 at $7.45 \mathrm{~m}$ below surface), a diagenetic zone (z2 at $3.35 \mathrm{~m}$ below surface), and an orthogonal set of subvertical fractures $\left(\mathrm{N} 75^{\circ} \mathrm{E}\right.$ and $\left.\mathrm{N} 25^{\circ} \mathrm{W}\right)$. Estimates of hydraulic conductivity have a bimodal distribution-high-conductivity fractures and lower-conductivity rock matrix.

The $11 \times 10-\mathrm{m}$ area, over which the high-resolution 3D GPR data were acquired, includes nine wells installed by the Wisconsin Geological and Natural History Survey (WGNHS) for prior hydrologic tests (Figure 1). Trace spacing was $0.1 \times$ $0.1 \mathrm{~m}$, and $200-\mathrm{MHz}$ frequency antennas were used. Good quality data were recorded to 160 ns two-way traveltime (approximately $8 \mathrm{~m}$ below surface). Figure 2 shows distinct radar horizons, delineated in three dimensions, that correlate to horizontal flow conduits including fractures ( $\mathrm{f} 1, \mathrm{f} 2$, and $\mathrm{f} 3$ ), a dissolution zone (z1), and a diagenetic zone (z2). The top of the saturated zone (wt) was $2 \mathrm{~m}$ below the ground surface during data acquisition.

Figure 3 displays GPR data line 54 (which intersects wells 11,13 , and 16), the stratigraphic log of well 5 , and the hydraulic conductivity $(\mathrm{K})$ profile of well 5 . Horizontal fractures $\mathrm{f} 2$ and $\mathrm{f} 3$, identified by maximum deflections on the caliper $\log$ and minimum deflections on the resistivity curve, correlate to strong continuous GPR reflections and zones of high hydraulic conductivity. These horizontal fractures (also referred to as bedding-plane discontinuities) occur at facies boundaries and across contrasting lithologies, and are enlarged by dissolution. As indicated by the stratigraphic log,

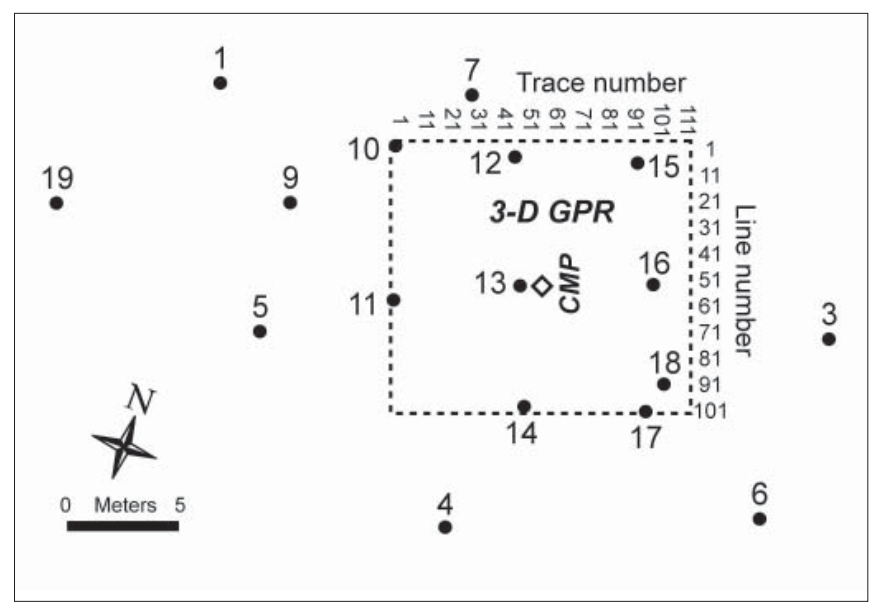

Figure 1. Map of Bissen Quarry displaying the 3D GPR grid coverage (dashed outline), CMP survey midpoint (open diamond), and the WGNHS wells (solid circles).

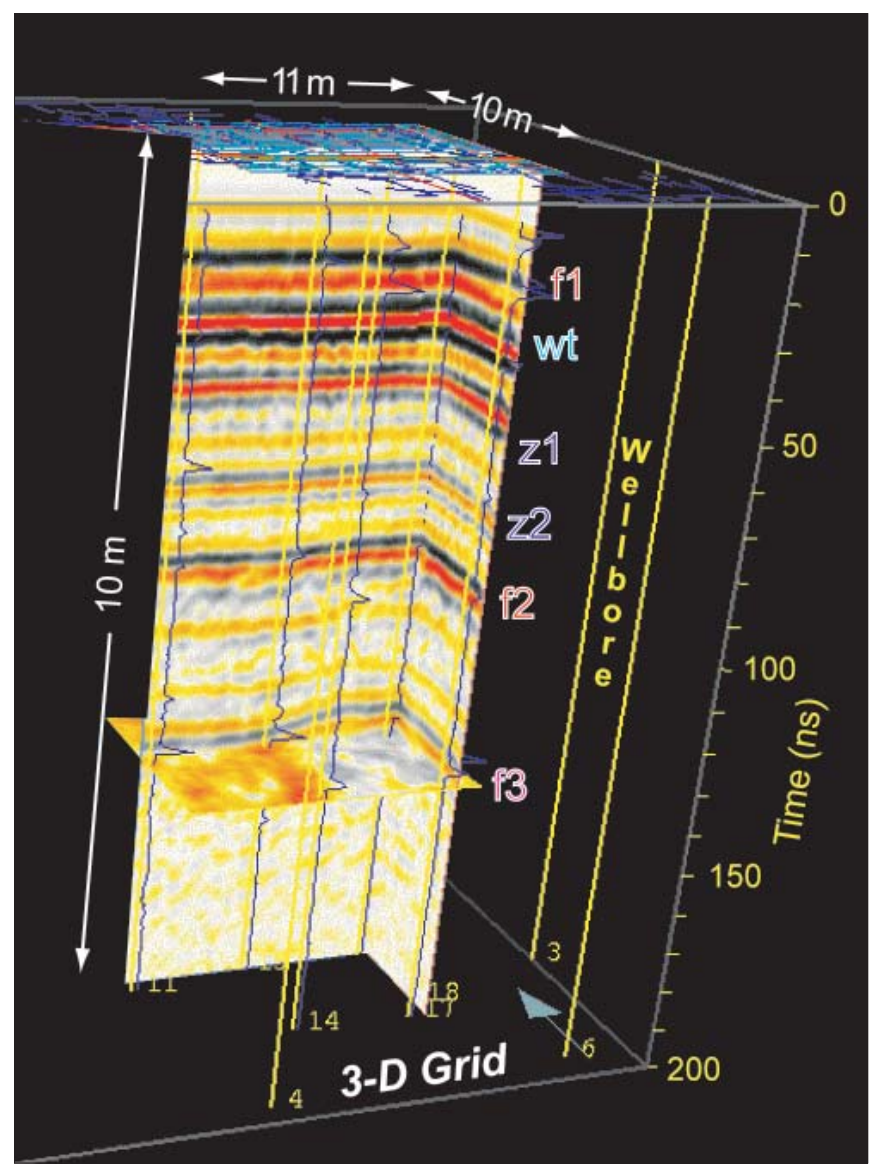

Figure 2. 3D GPR data and caliper log curves (blue). Distinct reflections correlate spatially to horizontal flow conduits such as fractures ( f1, f2, and f3), a dissolution zone (z1), and a diagenetic zone ( $z 2$ ). The top of the saturated zone ( $w t)$ is $2 \mathrm{~m}$ below the surface. 


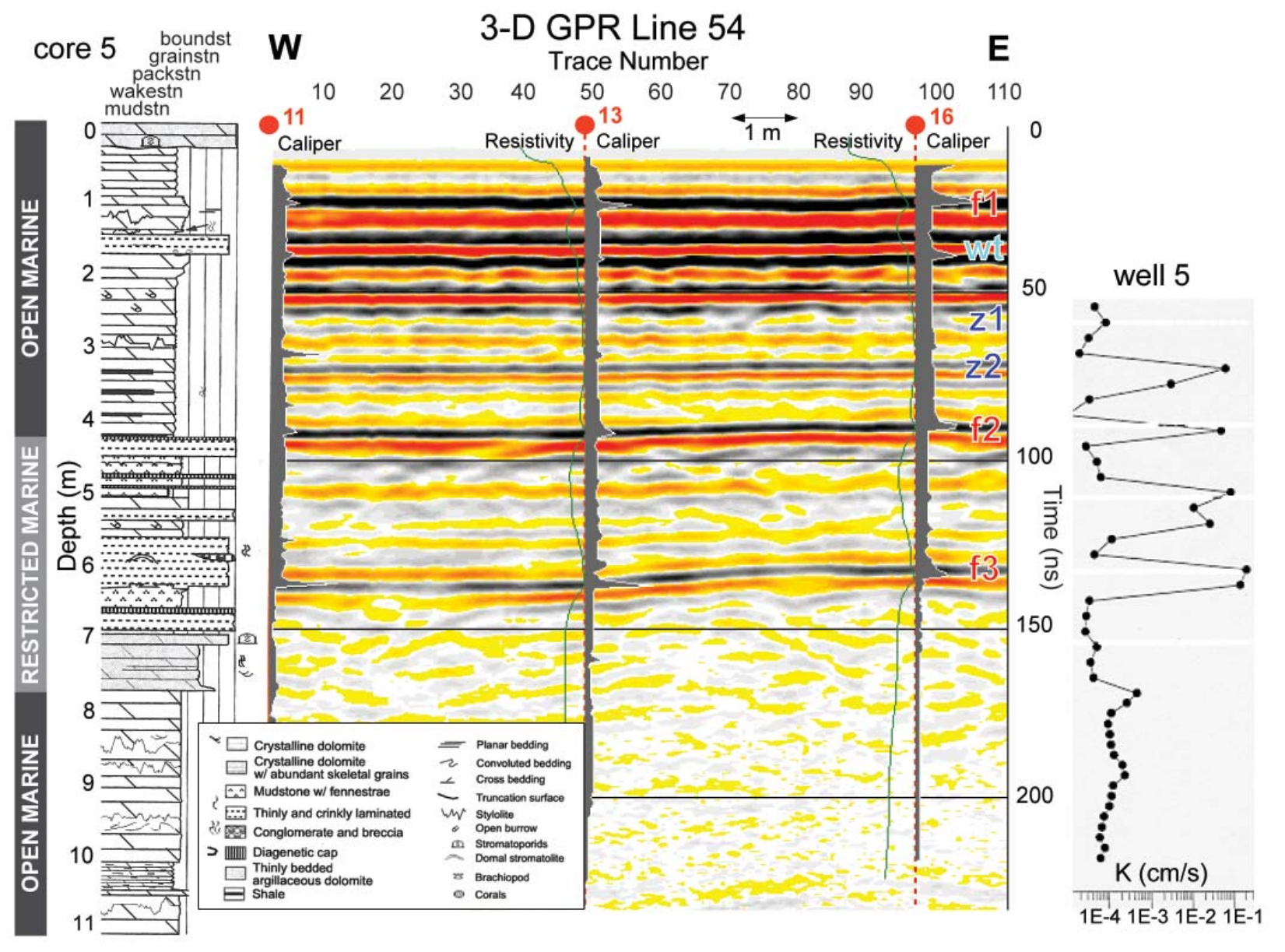

Figure 3. 200-MHz data from line 54 intersecting wells 11, 13, and 16. Stratigraphic log (left) and hydraulic conductivity profile (right) of well 5, and well log resistivity and caliper curves are tied to the GPR profile. Distinct radar reflections correlate with prominent hydrologic features. (Borehole data provided by WGNHS. Hydraulic conductivity from Muldoon and Bradbury. Stratigraphic log from Simo et al.)

the top $4.2 \mathrm{~m}(-0-85 \mathrm{~ns})$ of the section corresponds to open marine facies (middle shelf, coarser-grained with more massive bedding); the middle section (4.2-7.8 $\mathrm{m}$ or $-85-160 \mathrm{~ns})$ is a restricted marine cyclic facies (inner shelf, finer-grained, thin-bedded, shallowing upward depositional cycles); and the lower section (below $7.8 \mathrm{~m}$ or $-160 \mathrm{~ns}$ ) is another open marine facies.

GPR reflections corresponding to the open marine facies exhibit greater lateral continuity than those corresponding to the restricted marine facies, which show significant vertical variation in lithology. The dissolution zone (z1, at $2.7 \mathrm{~m}$ or $-56 \mathrm{~ns}$ ), imaged as a discontinuous GPR reflection, is characterized by poorly interconnected large vugs and corresponds to a small increase in the hydraulic conductivity profile of well 5. Figure 4a, a photograph of the open marine facies exposed at the quarry wall approximately $1 \mathrm{~m}$ above ground, shows a large vug dissolution zone $(\mathrm{z})$ and a prominent bedding-plane discontinuity (f). Those features are thought to be analogous to the open marine features $\mathrm{z} 1$ and $\mathrm{f} 2$ imaged by GPR at $50-100$ ns. Figure $4 \mathrm{~b}$, a section of the $3 \mathrm{D}$ volume with thickness of $30 \mathrm{~cm}$ and centered at $\mathrm{z} 1(58 \mathrm{~ns})$, shows reflector variability through the large vug dissolution zone. Yellow regions correspond to negative reflection amplitudes, indicating increased water content relative to positive amplitudes (black and gray areas). The yellow regions, interpreted as water-filled vugs, appear poorly interconnected, which is consistent with the relatively low hydraulic conductivity of the dissolution zone. The diagenetic zone (z2, at $3.35 \mathrm{~m}$ or $72 \mathrm{~ns}$ ), characterized by abundant molds and small vugs, has enhanced porosity (i.e., high water content) which causes a strong and continuous GPR reflection. This zone corresponds to a conduit with high hydraulic conductivity. The hydraulically conductive interval at $110-130 \mathrm{~ns}$ is poorly resolved by the radar data (e.g., Figure 3), possibly due to the extensive lithologic variation in the restricted marine facies.

Vertical fractures can provide connectivity to laterally extensive horizontal flow conduits and therefore are important hydrologic features. Vertical fractures were visible on the quarry floor, the quarry wall (e.g., Figure 4a), and they were identified by tracer tests. However, vertical fractures at Bissen Quarry are thin, near vertical, and do not offset bedding planes. Thus, the discontinuity was not large enough to be detected by the reflection geometry in the $3 \mathrm{D}$ grid.

Muldoon et al. (2001) studied the hydrostratigraphy of the Byron dolomite and demonstrated that matrix hydraulic conductivity is controlled by textural variations, with the 
Figure 4. (a) Photograph of the Byron dolomite open marine facies (1 $m$ above the surface), showing a dissolution zone with large vugs $(z)$ and a horizontal bedding-plane discontinuity $(f)$. (b) Slice of the 3D GPR volume centered at 58 ns through dissolution zone $z 1$ and with large poorly interconnected vugs. Yellow areas correspond to negative amplitudes, indicating increased water content. Wellbores (yellow lines) are shown intersecting the horizon. (c) Section of GPR line 76 through the open marine facies: $z 1$ = dissolution zone; $z 2=$ diagenetic zone; $f 2=$ horizontal fracture.

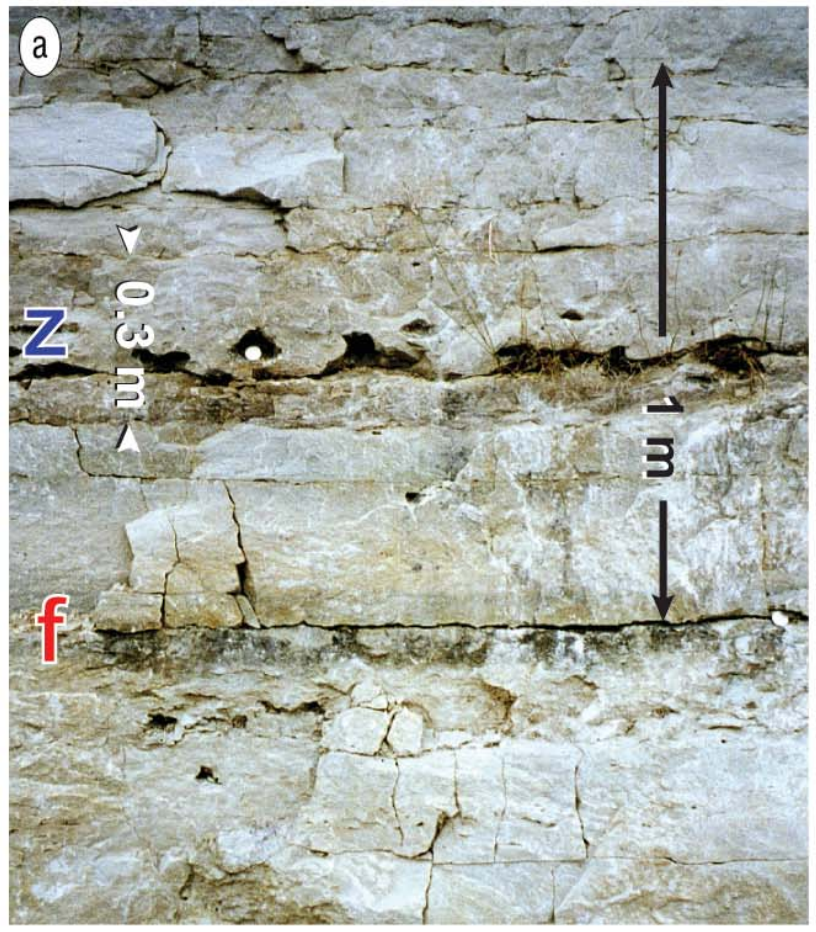

coarser-grained open marine facies having higher hydraulic conductivity than the finer-grained restricted marine facies. Fractures and bedding-plane discontinuities form throughout the Byron dolomite, with the restricted marine facies exhibiting a greater density of permeable features. In the open marine facies, those features form between units of contrasting texture. In the restricted marine facies, they form between contrasting lithologies.

EM wave velocity is primarily controlled by the water content of the formation matrix. Thus, velocity analysis of the saturated Byron dolomite matrix can yield information about the variations of matrix porosity and distribution of lithofacies. Three 200-MHz, 150-fold, CMP surveys were acquired at Bissen Quarry. Figure 5 displays the CMP survey adjacent to well 13 and its corresponding velocity spectrum. The reflected waves display hyperbolic moveout that depends on the EM wave velocity. The high-fold CMP profile yields good-quality velocity information to approximately $350 \mathrm{~ns}$ two-way traveltime $(\sim 17$ m below surface) despite low reflection signal strength. The velocity spectrum shows four distinct stacking-velocity segments that correlate spatially to the alternating open and restricted marine carbonate facies identified in core 19 (stratigraphic log from Simo et al., 1998).

The velocity segments in the CMP profile are differen-
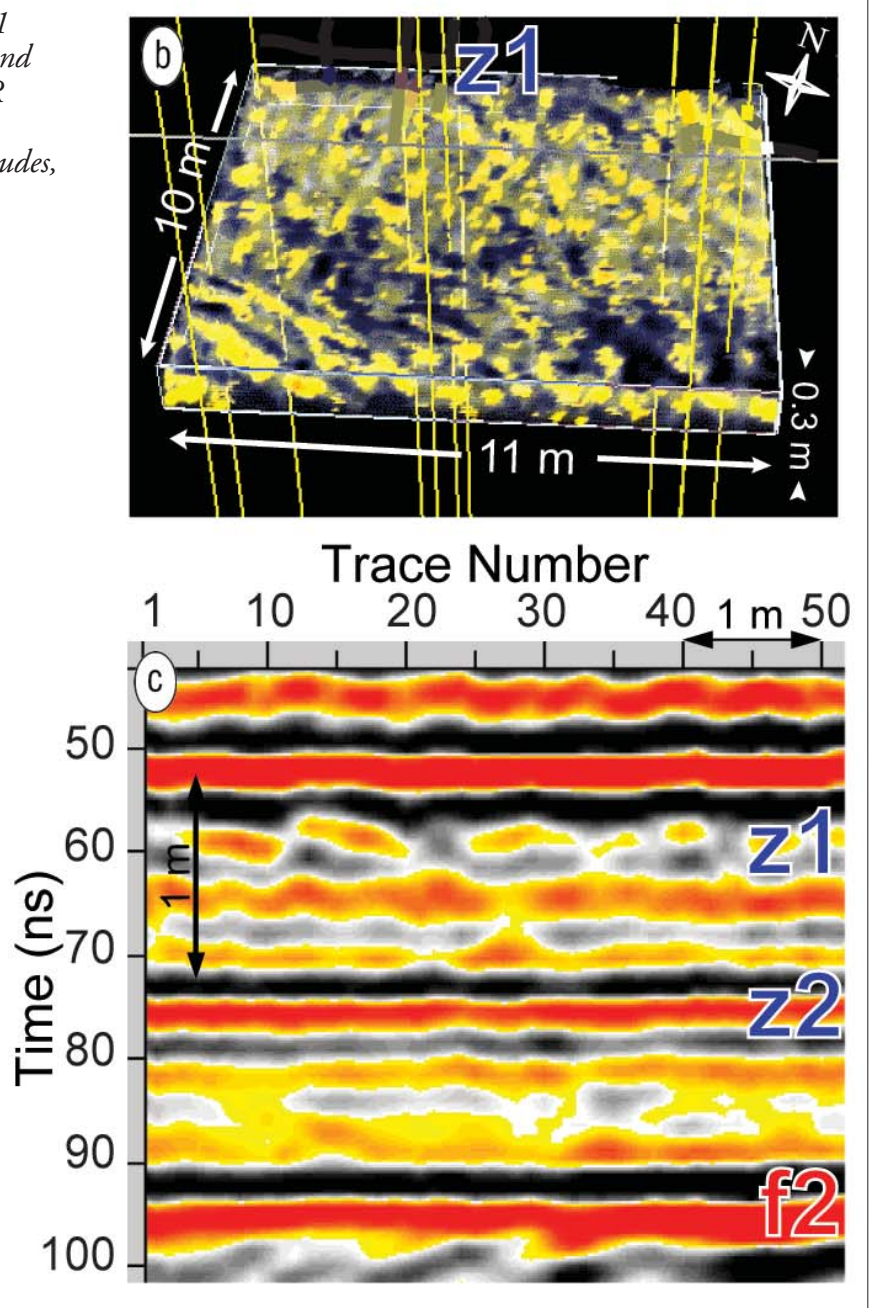

tiated by sharp velocity contrasts that coincide with facies change. The open marine facies display little variation in velocity, only a small increasing trend upward. The restricted marine facies exhibit greater velocity variations with velocity increase followed by velocity decrease. This change in the velocity trend is consistent with the cyclic character and greater lithologic variation in the restricted marine facies. The vertical velocity resolution in Figure 5 is 10 ns two-way traveltime, which corresponds approximately to $0.5 \mathrm{~m}$ of vertical velocity resolution. Stacking velocity can give an estimate of interval velocity, which can yield a dielectric constant profile of the subsurface. In the saturated portion of the Byron dolomite, increasing EM wave velocity indicates decreasing volumetric water content, which in turn indicates decreasing pore space.

By using GPR velocity spectrum trends and velocity breaks, open marine and restricted marine facies can be differentiated. It should be noted that the velocity spectrum of Figure 5 better defines lithofacies, and the reflection profile of Figure 3 identifies structural features. Both data sets offer insights about the distribution of flow units and flow conduits in the Byron dolomite.

\section{GPR amplitude response to fracture aperture}

Flow through a fracture is proportional to the third power 


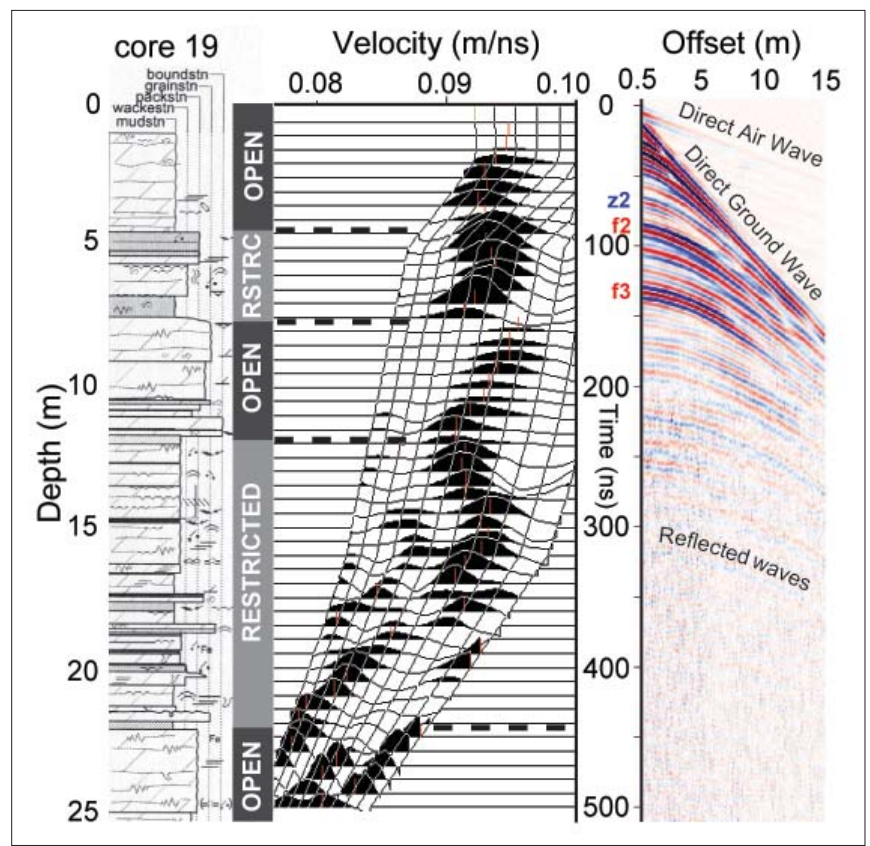

Figure 5. Stratigraphic log (left), GPR velocity spectrum (middle), and corresponding 200-MHz CMP profile (right). GPR stacking velocity segments correlate to distinct open and restricted marine lithofacies and are separated by sharp velocity breaks identified by horizontal dashed lines (stratigraphic log from Simo et al.).

of the fracture aperture (Snow, 1969); thus fracture aperture variations, fracture connectivity, and channeling in fractures affect the hydraulic properties of a formation. Using GPR to detect fractures offers information about the location and structure of those features but only limited information about the hydraulic properties of the flow conduit. EM theory shows that the amplitude of a GPR reflection from a thin layer is a function of layer thickness, the dielectric properties of the media, frequency, angle of incidence, and polarization of the wavefield. For near-normal incidence angles, as with the data at Bissen Quarry, wavefield polarization effects are negligible. Reflection amplitude will increase from zero for zero-layer thickness to a maximum value for layer thickness approximately equal to one-fourth the wavelength in the medium filling the fracture. Prior studies show that GPR signal amplitude can be related to a fracture's aperture (Gregoire et al., 2003), fluid content (Lane et al., 2000), and water saturation (Tsoflias et al., 2001).

Variation in fracture reflection amplitude was examined to gain insights about aperture variability along beddingplane discontinuities at Bissen Quarry. Figure 6 shows amplitude maps of GPR reflections corresponding to fractures f2 and f3. These water-saturated horizontal reflectors show approximately six-fold variation in signal amplitude within meter-scale lateral distances. Outcrop observations at Bissen Quarry (e.g., Figure 4a) show centimeter-scale variability of aperture within meter-scale lateral separation $(2 \mathrm{~cm}$ to closed along feature $\mathrm{f}$ ). Dissolution enhancement of flow conduits can result in even greater aperture variability.

Forward modeling of GPR amplitude response to fracture aperture assessed the scale of aperture variation required

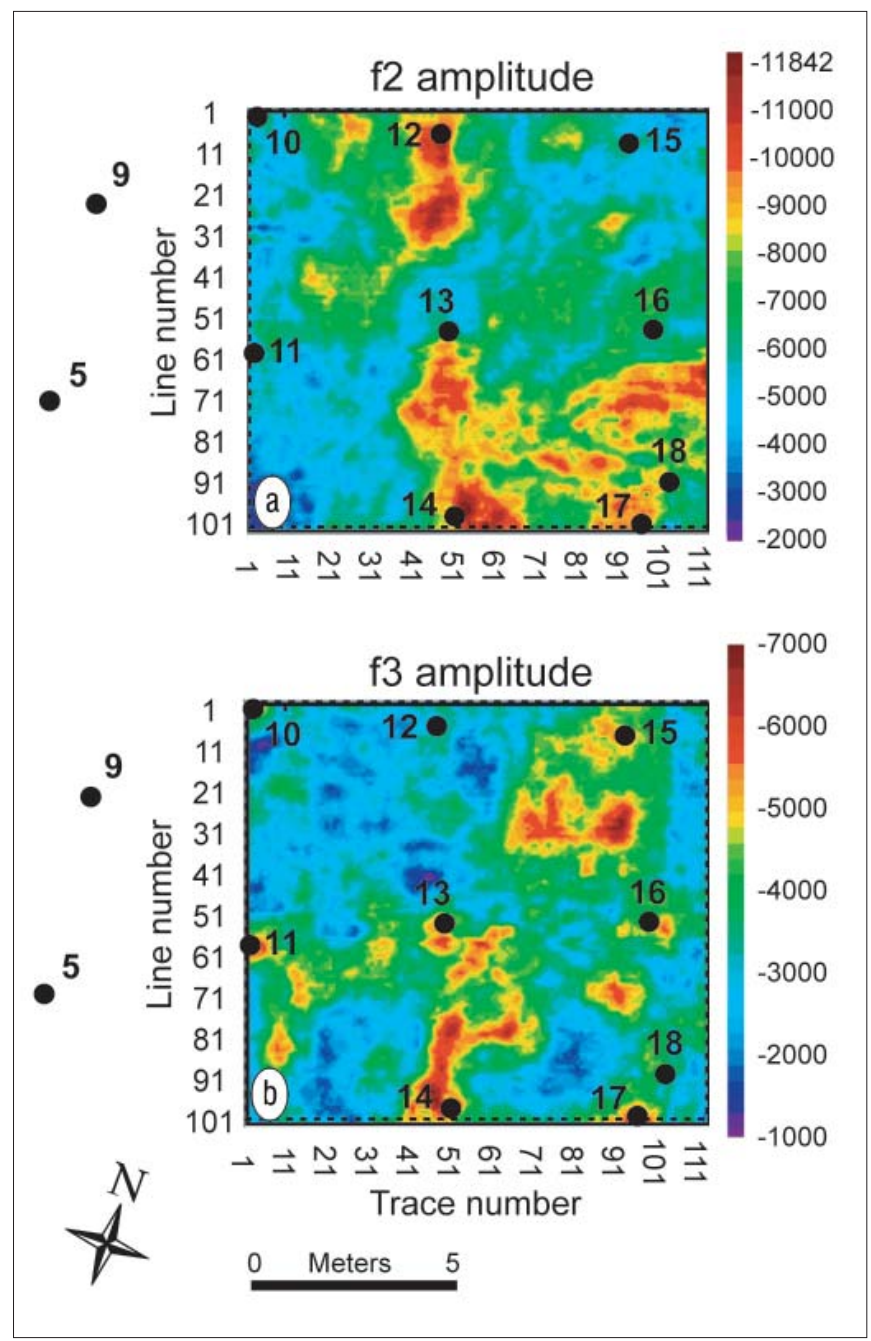

Figure 6. GPR amplitudes from water-saturated fractures: (a) f2 at $4.25 \mathrm{~m}$ below surface and (b) $f 3$ at $6.4 \mathrm{~m}$ below surface. Solid circles indicate wells.

to generate amplitude changes comparable to the ones at Bissen Quarry. Figure 7a plots reflection coefficient magnitude versus fracture aperture for a wedge model with the dielectric properties of the Byron dolomite and containing a freshwater-saturated fracture. The computations consider a $200-\mathrm{MHz}$ frequency, parallel-polarized, plane wave incident to the wedge model at angles of $10^{\circ}$ (e.g., f2) and $6.6^{\circ}$ (e.g., f3). The analytical models show that a change in fracture aperture from 0 to $2 \mathrm{~cm}$ could change the magnitude of the reflection coefficient from 0 to 0.7 ; a change in aperture from 1 to $3 \mathrm{~cm}$ almost doubles the reflection coefficient magnitude. Two-dimensional finite-difference time-domain simulations of $200-\mathrm{MHz}$ GPR signals impinging at $10^{\circ}$ to centimeterscale water-saturated horizontal fractures in dolomite also show GPR amplitude nearly doubling for a change in aperture from 1 to $3 \mathrm{~cm}$ (Figure $7 \mathrm{~b}$ ).

Analytic computations and numerical models are in good agreement and indicate that the high negative amplitudes and amplitude variations observed along fracture surfaces can be interpreted as areas of centimeter-scale variation of the aperture of a saturated flow conduit. As observed in the open marine facies portion of the section (Figure 4a, feature f), those 

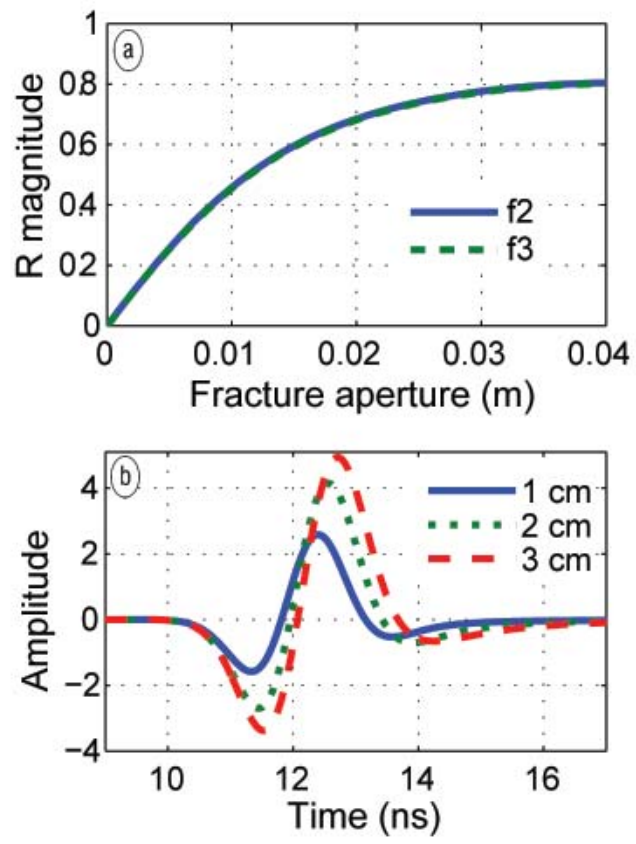

Figure 7. (a) Reflection coefficient magnitude versus water-saturated fracture aperture in dolomite for a $200-\mathrm{MHz}$ plane wave incident to fracture planes $f 2$ and $f 3$. (b) $2 D$ FDTD simulations of a $200-\mathrm{MHz}$ GPR signal at incident angle of $10^{\circ}$ to a $1-\mathrm{cm}, 2-\mathrm{cm}$, and 3-cm water-saturated horizontal fracture in dolomite.

fractures have variable aperture and limited lateral extent. Thus, the amplitude variation along fracture surfaces could provide information on the spatial variability of fracture aperture. The amplitudes in Figure 6 suggest that $\mathrm{f} 3$ may have increased hydraulic conductivity oriented NS, and f2 may have a flow boundary trending in the same direction.

Controlled gradient tracer tests reveal the high degree of flow heterogeneity in the fractured Byron dolomite and help illustrate the use of GPR for assessing flow properties. Muldoon and Bradbury (1998) reported that a tracer injected in well 15 at level $\mathrm{f3}$, while pumping in well 12 , was not detected in well 12 but was detected at level $\mathrm{f} 3$ in well 16 . Figure $6 \mathrm{~b}$ shows well 12 positioned in a low-amplitude region, suggesting closed or restricted conduits; wells 15 and 16 are in an area with higher amplitudes, suggesting open conduits more likely to be in communication.

A tracer injected in well 15 at level f2, while pumping in well 17 level f2, moved through a vertical fracture to level f3 in well 15 and then entered the formation. Highly diluted tracer was detected at multiple levels in wells 16 and 17 but not in well 18. Muldoon and Bradbury suggested that the bulk of the tracer did not move as expected towards monitor wells 16, 17, and 18, but rather in another direction. At the injection location, low $\mathrm{f} 2$ amplitudes surround well 15 , suggesting closed horizontal flow conduits. High amplitudes at borehole 15 level $\mathrm{f3}$ suggest open conduits and support the observation that the bulk of the injected tracer moved

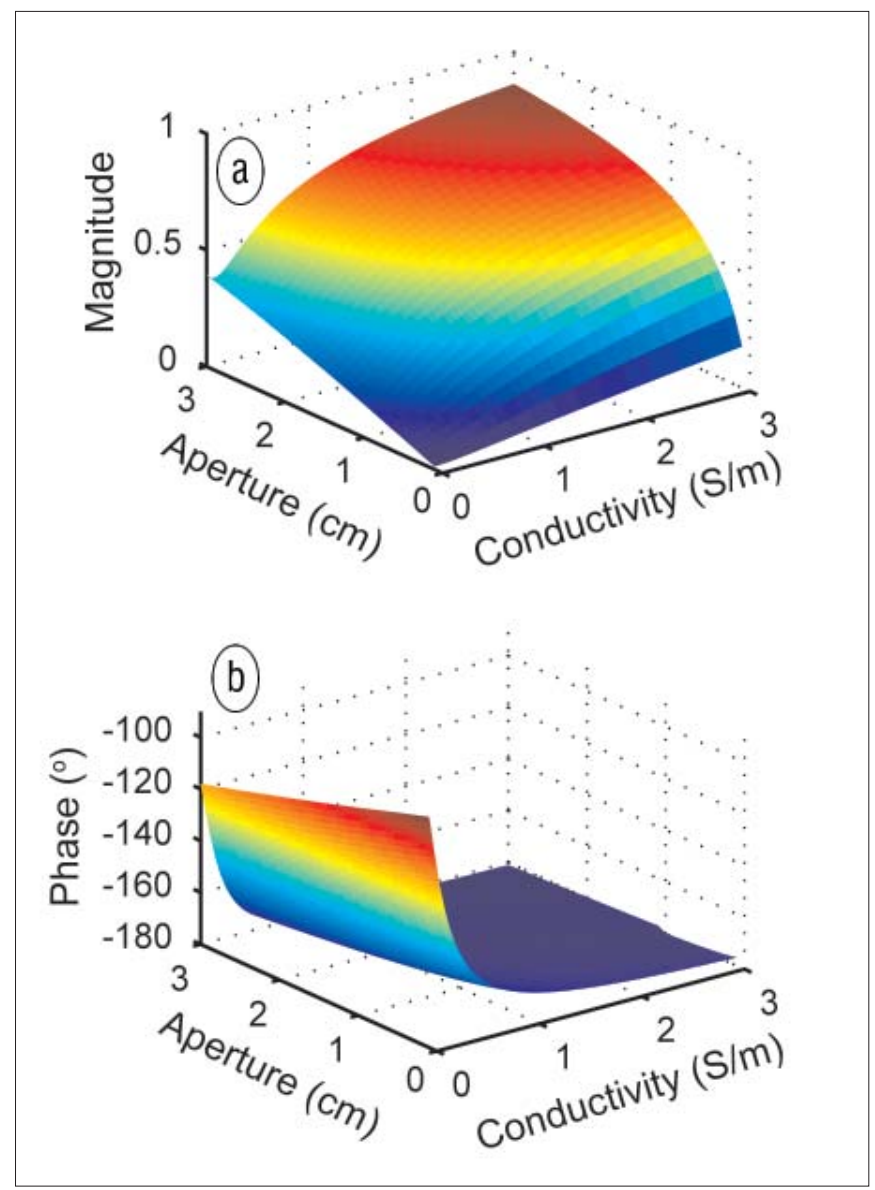

Figure 8. (a) Reflection coefficient magnitude and (b) reflection coefficient phase as a function of fracture aperture and water electrical conductivity for a $50-\mathrm{MHz}$, parallel-polarized EM wave impinging at an angle of $7.5^{\circ}$ to the fracture plane.

through that region. Furthermore, the high $\mathrm{f} 3$ amplitudes trending through wells 13 and 14 (not monitored) may have provided the conduits for most of the tracer's movement, rather than the lower-amplitude regions of monitoring wells 16, 17 and 18.

Another tracer injected in borehole 9 level f3, while pumping from borehole 14 level $\mathrm{f3}$, was detected in borehole 14 but not in borehole 11. Muldoon and Bradbury concluded that bypassing well 11 indicates that flow in those horizontal fractures is within preferential pathways, or channels. Amplitude patterns in Figure 6 suggest such pathways.

It is recognized that submillimeter conduit apertures can contribute significantly to flow while causing indiscernible changes in GPR reflection amplitude. Furthermore, vertical fractures are important flow conduits. However, it is suggested, that despite resolution limitations, GPR amplitude response can offer valuable insights to fractured formation hydraulic properties as evidenced by the agreement between GPR amplitude data in Figure 6 and the tracer test results reported by Muldoon and Bradbury.

GPR phase response to electrical conductivity in fracture fluid WGNHS hydrologic studies identified zone $\mathrm{f} 3$ as the most important regional flow horizon. Although GPR amplitude 


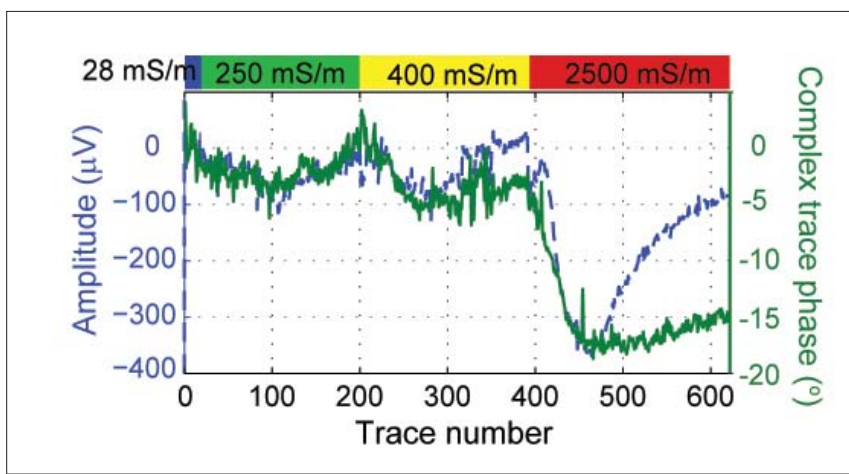

Figure 9. Differences in 50- $\mathrm{MHz}$ fracture reflection amplitude (dashed blue curve) and complex trace phase angle (solid green curve) from background salinity conditions $(28 \mathrm{mS} / \mathrm{m})$. Electrical conductivity of borehole fluid prior to each injection is at the top of the graph.

in Figure 6 can be related to conduit mechanical aperture, it is a static image with no information about the actual, real-time flow of fluids and transport of mass through the fracture. Increases in GPR reflection amplitude have been observed when saline tracers are injected in freshwater-filled fractures. However, the GPR signal amplitude alone is not sufficient for determining tracer concentration (i.e., mass transport) because amplitude is also a function of fracture aperture, which is not known in most field investigations. EM theory predicts that electrically conductive media yield complex reflection coefficients that physically imply a phase shift. In this study, it is shown that the phase of the GPR signal responds to fluid conductivity changes in a characteristic and predictable manner, analogous to the change in signal amplitude, and therefore can aid in the characterization of fracture flow properties.

Figure 8 plots analytical computations of $50-\mathrm{MHz}$ EM wave reflection coefficient magnitude and phase for a $0-3 \mathrm{~cm}$ aperture fracture saturated with water and possessing electrical conductivity of $0-3 \mathrm{~S} / \mathrm{m}$. Reflection coefficient magnitude increases as a function of increasing fracture aperture and the water's electrical conductivity. Reflection coefficient phase exhibits a stronger dependence on electrical conductivity than aperture, with a phase decrease (phase lag) of up to $-90^{\circ}$ (mostly over the conductivity range of $0-1.5 \mathrm{~S} / \mathrm{m}$ ). It is evident that any single value of the modeled reflection coefficient magnitude corresponds to numerous aperture-conductivity pairs. Considering the phase of GPR signals improves our ability to decouple aperture and electrical conductivity from the GPR response.

The phase response of GPR to electrical conductivity changes in fracture fluid is illustrated by data acquired by Tsoflias and Becker (2007) during saline tracer injection tests at the Altona Flat Rock test site, a fractured lithified quartzose sandstone northwest of Plattsburgh, New York. A hydraulically conductive horizontal fracture $7.6 \mathrm{~m}$ below ground surface was investigated by Talley et al. (2005) to monitor saline tracer migration using GPR, and by Tsoflias and Becker (2008) to investigate the response of multifrequency GPR to the salinity of fracture water. A stationary $50-\mathrm{MHz}$
GPR system positioned $3.6 \mathrm{~m}$ downgradient from an injection borehole recorded data continuously while three sequential tracer injections of varying salinity were released into the water-saturated fracture. Groundwater flow was controlled by the natural gradient. Background groundwater electrical conductivity was $28 \mathrm{mS} / \mathrm{m}$. The three saline tracers had electrical conductivities of 250, 400, and $2500 \mathrm{mS} / \mathrm{m}$. Electrical conductivities were measured at the injection borehole prior to the release of the tracer. It should be noted that loss of tracer mass due to fracture channeling, mixing with freshwater, and dispersion, as well as uncertainty in the direction of flow, results in poorly controlled tracer concentration at the location beneath the GPR antennas. However, it is expected that with each tracer injection, electrical conductivity increased in the fracture fluid from background, to low, intermediate, and high conductivity.

Figure 9 plots fracture reflection amplitude and complex trace phase angle differences from the mean background amplitude and phase during the tracer test. Corresponding electrical conductivities measured at the injection borehole are shown at the top of the graph. As predicted by the analytical models, for a constant aperture (i.e., stationary GPR imaging), increasing electrical conductivity in the fluid results in increasing GPR signal magnitude and phase lag. The small phase change (up to $-18^{\circ}$ ) between the saline tracer releases and background water suggest that the tracers were highly diluted in the region below the GPR antennas. Each tracer injection was sensed remotely by GPR signal amplitude and phase, giving the appearance of tracer concentration breakthrough curves analogous to tracer observations typically obtained in wells that monitor groundwater flow.

\section{Summary and conclusions}

Experiments at hydrologic test sites illustrate how GPR is helping gain insights about the heterogeneous flow properties of dual-porosity units. Three-dimensional GPR surveys imaged varying carbonate lithofacies, lithologic discontinuities, dissolution zones, and horizontal fractures. Velocity analysis of CMP data identified velocity variations correlating to alternating open and restricted marine facies. When employed along with hydrologic and stratigraphic information, 3D GPR imaging and velocity analysis can help define the hydrostratigraphy of a site, which controls the distribution of flow units and flow conduits.

Variation of GPR reflection amplitude along prominent flow conduits suggests centimeter-scale fracture aperture variation. Fracture reflector amplitude and phase show characteristic and predictable responses to the electrical conductivity of fracture fluid. GPR signal amplitude and phase used with full waveform inversion methods could yield quantitative estimates of fracture aperture and saline tracer concentration, two parameters critical to the accurate characterization of flow in fractures.

The hydraulic properties of fractured rock are highly variable and difficult to predict. GPR imaging along with borehole observations and hydraulic tests could assist in quantitative characterization of flow in fractures at small scales (i.e., 
site scale) and provide meaningful parameters for discrete fracture flow modeling.

Suggested reading. "Ground penetrating radar for high-resolution mapping of soil and rock stratigraphy" by Davis and Annan (Geophysical Prospecting, 1989). "Improving resolution and understanding controls of GPR response in carbonate strata: Implications for attribute analysis" by Franseen et al. (TLE, 2007). "3D ground-penetrating radar applied to fracture imaging in gneiss" by Grasmueck (Geophysics, 1996). "GPR abilities for the detection and characterization of open fractures in a salt mine" by Gregoire et al. (Near Surface Geophysics, 2003). "Evaluation of ground-penetrating radar to detect free-phase hydrocarbons in fractured rocks-results of numerical modeling and physical experiments" by Lane et al. (Ground Water, 2000). "Use of ground-penetrating radar for 3D sedimentological characterization of clastic reservoir analogues" by McMechan et al. (Geophysics, 1997). "Tracer study for characterization of groundwater movement and contaminant transport in fractured dolomite" by Muldoon and Bradbury (Wisconsin Geological Natural History Survey Open File Report, 1998). "Correlation of hydraulic conductivity with stratigraphy in a fractured dolomite aquifer, northeastern Wisconsin, USA" by Muldoon et al. (Hydrogeology Journal, 2001). "Stratigraphy and sedimentology of the silurian dolostones, Door County, Wisconsin" by Simo et al. (SEPM Research Conference, Fluid Flow in Carbonates: Interdisciplinary Approaches, 1998). "Anisotropic permeability of fractured media" by Snow (Water Resources Research, 1969). "Four dimensional mapping of tracer channelization in subhorizontal bedrock fractures using surface ground penetrating radar" by Talley et al. (Geophysical Research Letters, 2005). "Monitoring pumping test response in a fractured aquifer using ground penetrating radar" by Tsoflias et al. (Water Resources Research, 2001). "Multifrequency investigation of GPR amplitude and phase response to fracture fluid salinity" by Tsoflias and Becker (SEG 2007 Expanded Abstracts). "Ground-penetrating radar response to fracture fluid salinity: Why lower frequencies are favorable for resolving salinity Changes" by Tsoflias and Becker (Geophysics, 2008). THE

Acknowledgments: I am grateful to Maureen Muldoon, Ken Bradbury, Matt Becker, and Greg Baker for sharing their knowledge and geohydrologic insights from Bissen Quarry and Altona Flat Rock that assisted the evaluation and interpretation of the GPR data. I thank Ivan Bissen and the Miner Institute for allowing access to the test sites. This work was funded in part by the American Chemical Society Petroleum Research Fund (PRF 43401-G8) and the National Science Foundation (EAR 0345445).

Correspondingauthor: tsoflias@ku.edu 